\title{
artigo
}

\section{Teleatendimento como ferramenta de apoio profissional: acolhimento e escuta emocional na pandemia COVID-19}

Tele-service as a professional support tool: welcome and emotional listening in pandemic COVID-19

Tele-servicio como herramienta de apoyo profesional: bienvenida y escucha emocional en pandemia COVID-19

\section{RESUMO}

Objetivo: Relatar a experiência de um projeto de teleatendimento na escuta emocional de profissionais de uma Organização Social em Saúde na Pandemia. Método: Relato de experiência da implantação de um projeto de Acolhida Emocional para profissionais de saúde na cidade de Fortaleza, Ceará, Brasil, como estratégia de apoio aos funcionários durante a Pandemia da COVID-19 no período de maio a julho de 2020. Resultados: Registrados 130 atendimentos, abrangendo 49 funcionários. 0 teleatendimento foi uma boa solução para oportunizar a escuta durante Pandemia. Conclusão: Escuta qualificada por um psicólogo na ajuda aos funcionários na pandemia foi relevante devido à carência de cuidados voltados ao trato psicológico dos profissionais da área da saúde. $O$ uso de Tecnologia de Informação e Comunicação teve papel fundamental na aproximação do profissional voluntário com o funcionário da instituição, que se encontravam apreensivos com a situação de Pandemia e o risco diário de contaminação com o vírus.

DESCRITORES: Voluntários; Saúde mental; Angústia Psicológica; Tecnologia da Informação e Comunicação; Profissionais da Saúde.

\section{ABSTRACT}

Objective: To report the experience of a telemarketing project in the emotional listening of professionals from a Social Organization in Health in Pandemic. Method: Experience report of the implementation of an Emotional Reception project for health professionals in the city of Fortaleza, Ceará, Brazil, as a strategy to support employees during the COVID-19 Pandemic period from May to July 2020. Results: 130 cases were registered, covering 49 employees. The call center was a good solution to provide an opportunity to listen during Pandemic. Conclusion: Listening qualified by a psychologist in helping employees in the pandemic was relevant due to the lack of care focused on the psychological treatment of health professionals. The use of Information and Communication Technology played a fundamental role in bringing the volunteer professional closer to the institution's employee, who were apprehensive about the Pandemic situation and the daily risk of contamination with the virus.

DESCRIPTORS: Volunteers; Mental Health; PsychologicalDistress; Informationand Communication Technology; Health professionals.

\section{RESUMEN}

Objetivo: Informar la experiencia de un proyecto de telemarketing en la escucha emocional de profesionales de una Organización Social en Salud en Pandemia. Método: Informe de experiencia de la implementación de un proyecto de Recepción Emocional para profesionales de la salud en la ciudad de Fortaleza, Ceará, Brasil, como una estrategia de apoyo a los empleados durante el período de la Pandemia COVID-19 de mayo a julio de 2020. Resultados: Se registraron 130 casos, que cubrían a 49 empleados. El centro de llamadas fue una buena solución para brindar la oportunidad de escuchar durante la pandemia. Conclusión: La escucha calificada por un psicólogo en la ayuda a los empleados en la pandemia fue relevante debido a la falta de atención enfocada en el tratamiento psicológico de los profesionales de la salud. El uso de las Tecnologías de la Información y la Comunicación jugó un papel fundamental en el acercamiento del profesional voluntario al colaborador de la institución, quienes estaban aprensivos ante la situación de Pandemia y el riesgo diario de contaminación con el virus.

DESCRIPTORES: Voluntarios; Salud Mental; Distrés Psicológico; Tecnología de La Información y La Comunicación; Profesionales de la Salud.

RECEBIDO EM: 29/11/2020 APROVADO EM: 10/12/2020 


\section{Jefferson Rafael Marques Barbosa}

Graduado em Administração de Empresas pela Faculdade do Vale do Jaguaribe - FVJ. Analista de Desenvolvimento do Instituto de Saúde e Gestão Hospitalar - ISGH. Especialista em Gestão da Qualidade em Ambientes Hospitalares - ESP/CE. Especialista em Gestão em Saúde pela Universidade Estadual do Ceará- UECE.

ORCID: 0000-0001-6786-4848

\section{Jamille Soares Moreira Alves}

Graduada em Fisioterapia pela Universidade de Fortaleza - UNIFOR. Fisioterapeuta da Maternidade Escola Assis Chateaubriand - MEAC-UFC-EBSERH. Mestre em Ciências Fisiológicas pela Universidade Estadual do Ceará - UECE. MBA em Economia e Avaliação e Tecnologia em Saúde pela Faculdade de Educação em Ciências da Saúde - Hospital Alemão Oswaldo Cruz. Especialista em Fisioterapia Hospitalar pela Faculdade Integrada do Ceará. Especialista Profissional em Fisioterapia em Terapia Intensiva com área de atuação em Neonatologia e Pediatria pela Associação Brasileira de Fisioterapia Cardiorrespiratória e Fisioterapia em Terapia Intensiva - ASSOBRAFIR.

ORCID: 0000-0003-0213-1728

\section{Virgínia Angélica Silveira Reis}

Graduada em Medicina pela Universidade de Pernambuco - UPE. Mestre em Medicina Clínica pela Universidade Federal do Ceará - UFC. Especialista em Gestão da Qualidade em Ambientes Hospitalares - ESP/CE. Diretora de Ensino e Pesquisa do Instituto de Saúde e Gestão Hospitalar - ISGH. Assessora do Centro de Inteligência em Saúde do Estado do Ceará - CISEC.

ORCID: 0000-0002-4073-9008

\section{Luana Maria Lopes de Lima Figueiredo}

Graduada em Psicologia pela Universidade Federal do Ceará - UFC. Especialista em Acreditação em Saúde pela União Social Camiliana. Assessora Técnica do Instituto de Saúde e Gestão Hospitalar - ISGH.

ORCID: 0000-0002-3925-2622

\section{Rilka Barbosa Batista}

Graduada em Psicologia pela Universidade de Fortaleza - UNIFOR.Especialista em Gestão do Potencial Humano nas Organizações pela Universidade de Fortaleza - UNIFOR. Gerente de Desenvolvimento do Instituto de Saúde e Gestão Hospitalar - ISGH. ORCID: 0000-0003-4122-2403

\section{Fernanda Gadelha Severino}

Graduada em Fisioterapia pela Universidade de Fortaleza - UNIFOR. Mestre em Fisioterapia pela Universidade Federal do Rio Grande do Norte - UFRN. Especialista em Fisioterapia Cardiopulmonar pela Escola de Saúde Pública do Ceará - ESP/CE. MBA em Gestão e Inovação de Serviço de Saúde pela Pontifícia Universidade Católica do Rio Grande do Sul - PUCRS (em andamento). Docente da UNIFOR - CE.

ORCID: 0000-0001-5210-1856

\section{INTRODUÇÃO}

A pandemia da COVID-19 pelo novo coronavírus se mostrou como um dos maiores desafios sanitários em escala mundial das últimas décadas ${ }^{(1)}$. Trazendo relevantes impactos nas vidas dos indivíduos em nível mundial, chamando a atenção pelo alcance que teve e pela velocidade com a qual se disseminou ${ }^{(2)}$.

No Brasil, não foi diferente, com alguns agravantes particulares, dentre eles, a desigualdade social e a condição de populações vivendo em situação de aglomeração, favorecendo o aumento de casos. A importância e gravidade do novo vírus podem ser evidenciadas com o seu alcance veloz em curto período de tempo, sendo o primeiro caso confirmado em 26 de fevereiro e em 03 de março com um total de 500 casos suspeitos. A atualização do dia 12 de novembro de 2020 do Ministério da Saúde através do Painel Coronavírus, confirma casos e óbitos acumulados em 5.590 .025 e 161.106 , respectivamente e, um total de 5.064.344 casos recuperados ${ }^{(3)}$.

$\mathrm{O}$ insuficiente conhecimento científico sobre a COVID-19, sua velocidade de transmissão e sua letalidade, principalmente em populações mais vulneráveis, trouxe, consequentemente, um cenário de incertezas no seu enfrentamento e uma sobrecarga em toda máquina da saúde, requerendo dos profissionais à imposição de mudanças na rotina da prestação do cuidado ${ }^{(4)}$.

Para os profissionais de saúde que estão na linha de frente do enfrentamento à COVID-19, o impacto é ainda maior. Médicos, enfermeiros, técnicos, fisioterapeutas, psicólogos e assistentes sociais são algumas das categorias que desenvolvem serviços essenciais e estão expostas diariamente ao risco de contaminação ${ }^{(5)}$.

A chegada da pandemia ao país e a forma como vem evoluindo criaram novos desafios a pesquisadores, profissionais e instituições envolvidos na promoção da saúde dos trabalhadores, não podendo ser negligenciada as implicaçôes psicológicas, que podem ser mais duradouras e preva- 
lentes que o próprio acometimento pela COVID-19 $9^{(6,7)}$.

Além do adoecimento da população, surge então, a preocupação com os profissionais da área da saúde, que, indispensáveis, se tornaram um grande grupo vulnerável às consequências emocionais e psicológicas diante do enfrentamento à pandemia. Eles encaram rotinas exaustivas, onde o foco é dar tudo de si para cuidar dos pacientes infectados. Neste cenário, o amparo à saúde mental da linha de frente cabe também à coletividade, responsável por se informar, validar e respeitar quem cuida ${ }^{(7)}$.

Diante dessa realidade as instituições de saúde precisaram pensar e implantar ações, que, pudessem prestar um apoio emocional, terapêutico e psicológico aos profissionais da área da saúde, abrangendo não apenas àqueles da linha de frente, mas, também, àqueles que estão na retaguarda, apoiando profissionais na prestação de serviços assistenciais. Surge então em Fortaleza-CE, o projeto de Acolhida Emocional, fomentado por uma Organização Social em Saúde (OSS), juntamente com profissionais voluntários da área da psicologia, ratificando que o trabalho voluntário é previsto pela lei 9.608 de 18 de fevereiro de 1998, preconizando em seu artigo $1 .^{\circ}$, que, "considera-se serviço voluntário, para os fins desta Lei, a atividade não remunerada prestada por pessoa física a entidade pública de qualquer natureza ou a instituição privada de fins não lucrativos que tenha objetivos cívicos, culturais, educacionais, científicos, recreativos ou de assistência à pessoa"(8).

Com o lockdown as pessoas tiveram seu direito de circulação restrito, consequentemente, os conselhos de classe tiveram que retomar a discussão sobre atendimentos remotos, pois alguns pacientes não tinham condições de interromper os cuidados nesse período. Com isso o Conselho Federal de Psicologia (CFP) aprovou a Instrução Normativa 1, publicada em 17 de março de 2020 e a Resolução CFP 04 que instruem sobre o trabalho online durante este período e dispensa a necessidade de aguardar aprovação prévia
A necessidade de realização desse relato de experiência deu-se a partir da implantação e acompanhamento do projeto de Acolhida Emocional, com a prestação de atendimentos psicológicos aos profissionais da área da saúde, por teleatendimento, de forma voluntária por profissionais da área da psicologia, como apoio no enfrentamento

a pandemia da COVID-19. de cadastro, junto ao conselho, conforme previa a Resolução CFP no 11/2018, para iniciar os atendimentos nesta modalidade. Nesse momento o uso da tecnologia de informação e comunicação (TICs), através do teleatendimento, foi a solução para a acolhida emocional através da escuta terapêutica aos profissionais da área $\mathrm{da}$ saúde ${ }^{(9,10,11,12)}$.

A necessidade de realização desse relato de experiência deu-se a partir da implantação e acompanhamento do projeto de Acolhida Emocional, com a prestação de atendimentos psicológicos aos profissionais da área da saúde, por teleatendimento, de forma voluntária por profissionais da área da psicologia, como apoio no enfrentamento a pandemia da COVID-19.

A relevância deste relato está em apresentar como o projeto, realizado por uma Organização Social de Saúde (OSS), implementou o teleatendimento através do trabalho voluntário, como ferramenta de escuta psicológica durante o pico da Pandemia, trazendo relevância num contexto de isolamento social, sobrecarga e frenético trabalho por estes profissionais.

Nesse sentido, o presente artigo objetivou relatar a experiência do teleatendimento na escuta psicológica de profissionais da saúde de uma OSS, durante a Pandemia.

\section{MÉTODO}

Trata-se de um estudo descritivo de relato de experiência idealizado a partir da implantação e acompanhamento de um projeto de Acolhida Emocional focado na prestação de atendimento como forma de acolhida e escuta psicológica e emocional aos profissionais de saúde na cidade de Fortaleza, Ceará, Brasil, promovido por uma OSS, como estratégia de apoio aos funcionários durante a Pandemia da COVID-19.

A OSS em questão administra equipamentos de saúde do município e do estado, tendo unidades em Fortaleza e no interior do Ceará. O projeto foi disponibilizado a todos os funcionários. Para conhecimento e divulgação do projeto foram utilizadas como estratégias o uso de banners nas uni- 
dades de saúde, mídias digitais (Intranet, Instagram e WhatsApp), também, por meio, do Serviço de Engenharia, Segurança e Medicina do Trabalho (SESMT) e do Núcleo de Gestão de Pessoas (NGP), além de um trabalho feito junto às coordenações das unidades.

Disponibilizou-se 04 linhas telefônicas exclusivas para marcação de atendimentos, onde o funcionário realizava o contato telefônico junto ao SESMT buscando o agendamento para uma primeira acolhida com o psicólogo voluntário. Neste contato inicial o SESMT fazia as orientações quanto ao objetivo do projeto, sigilo e confidencialidade de todas as informações relativas ao atendimento, assim como, o modelo online de atendimento (via chamada de vídeo por aplicativo). Outra estratégia foi através da busca ativa realizada pelo SESMT aos funcionários afastados da instituição por suspeita de infecção da COVID-19.

Os atendimentos aconteceram no período compreendido entre maio e julho de 2020, de segunda-feira à sábado, por adesão voluntária, em três turnos (manhã, tarde e noite), buscando assim, oferecer ao público-alvo uma flexibilidade de dias e horários, visto que, levou-se em consideração a possibilidade da preocupação com intervençôes psicológicas ser considerada como um cuidado secundário. E contou com o voluntariado de 28 profissionais da área da Psicologia.

\section{RESULTADO}

No total foram realizados 130 atendimentos, junto a 49 funcionários, com duração média de 50 minutos cada atendimento. Apesar do projeto ter sido divulgado em todas as unidades, só tivemos adesão de parte das unidades sediadas em Fortaleza, o que talvez seja explicado devido ao fato de algumas unidades terem o serviço de psicologia e esses montaram um esquema de acolhimento aos seus profissionais localmente.

O perfil do profissional que foi acolhido pelo projeto foi funcionários administrativos da sede da OSS e das unidades básicas de saúde, além dos profissionais de 9 unidades de pronto atendimento (UPA). A maioria já tinha algum grau de sofrimento psicológico prévio, que foi potencializado durante esse momento de estresse.

\section{A escuta como modelo de atendi- mento psicológico no enfrentamen- to a pandemia da COVID-19}

O Conselho Federal de Psicologia (CFP) há tempos versa sobre escuta psicológica como uma possibilidade de atendimento - em outros contextos - corroborando para a escolha da estratégia pela OSS como meio de cuidar da saúde psicológica de seus funcionários ${ }^{(13)}$.

A escuta emocional se caracteriza por ser uma relação de cuidado, acolhedora e não invasiva, para a qual se requer a disposição de escutar, sempre respeitando o tempo de elaboração e relato do fato traumático, consistindo, também, em oferecer lugar e tempo para a expressão de desejos e demandas ${ }^{(14)}$.

Em contrapartida, a psicoterapia - não utilizada no projeto - tem como escopo de trabalho um processo científico de compreensão, análise, e intervenção que se realiza de forma sistematizada e controlada de métodos e técnicas psicológicas. Também, existe o estabelecimento de contrato entre profissional e paciente, e; possui um caráter de continuidade, já que o profissional deve fornecer, sempre que solicitado pela pessoa atendida ou seu responsável, informações sobre o desenvolvimento da psicoterapia, conforme o Código de Ética ${ }^{(15)}$.

Desde o início, quando surgiu a inquietação por parte da OSS o questionamento: "Como poderemos oferecer aos nossos funcionários um apoio para seus medos, angústias e incertezas neste cenário de pandemia e calamidade pública”. Houve sempre a preocupação com os preceitos éticos e técnicos do atendimento psicológico, principalmente, do ponto de vista da legalidade a diferenciação entre Acolhida/ escuta Emocional e Psicoterapia. Toda a crise gerada em consequência da pandemia deflagrou sofrimentos e a exposição de fragilidades humanas e sociais, com uma intensidade significativa para profis- sionais da área da saúde, que além de estarem dentro do contexto de pandemia, estão diariamente expostos aos riscos de contaminação no atendimento a população infectada pela COVID-19. Com isso, a OSS escolheu o modelo de escuta psicológica como ferramenta de apoio e suporte psicológico aos seus funcionários, na busca pelo alívio de fatores estressores oriundos da rotina de enfrentamento a pandemia e do próprio isolamento social e outras limitações impostas com vistas à redução da proliferação do vírus.

A escuta emocional/psicológica tem um escopo de modelagem de plantão psicológico, com uma proposta de consulta psicológica não diretiva, tendo como características a sua imediatez, disponibilidade do momento de emergência, da necessidade. A escuta emocional e psicológica é pensada e praticada, basicamente, como um modo de acolher e responder a demandas por ajuda psicológica. Outra característica, bem específica, do modelo de escuta psicológica é como ele acontece na prática, sendo delineado por três vertentes: a da instituição que oferece o serviço; a do profissional disponível para o não planejado, e; o cliente que busca auxílio para suas necessidades urgentes $(16,17)$.

A escuta emocional e psicológica realizada por meio de Tecnologias da Informação e da Comunicação (TIC) foi o meio que se mostrou mais viável, seguro e digno de apoio à saúde relacionada ao trato psicológico dos funcionários da OSS, com o objetivo de prestar de forma direcionada suporte e apoio aos seus funcionários, buscando atender a todas as orientações pertinentes do Conselho da área, sempre balizados nas condutas éticas, bem como, no sigilo e confidencialidade de todas as informações referentes aos atendimentos ${ }^{(18)}$.

\section{O papel e a responsabilidade da OSS na promoção da saúde psicológica dos profissionais durante a Pande- mia da COVID-19}

Devido à alta transmissibilidade do vírus, grande proporção de infectados, inexistência de vacina e de terapia medicamentosa comprovada, insuficiente 
cobertura de testes, duração prolongada dos quadros clínicos e as experiências de outros países explicam as decisóes que provocaram medidas de isolamento social determinando que só os serviços essenciais fossem mantidos. Ressaltando que, nesse contexto, para algumas categorias, a exemplo dos profissionais da área da saúde, houve intensificação das tarefas. Havendo, também, um grande volume de orientações para com a higiene, recomendado o uso de máscaras, álcool gel e lavagem constantes das mãos ${ }^{(19,20)}$.

Gerenciar em momentos de Pandemia os processos de trabalho dos profissionais da área da saúde, sejam administrativos ou assistenciais, envolve questões de mudanças nas tomadas de decisão, processos de trabalhos, práticas assistenciais, rotinas; além das questões, como: administração de recursos financeiros, afastamento da família e amigos, ameaças e agressões propriamente ditas, perpetradas por pessoas que buscam atendimento e não se sentem acolhidas; gerando nas equipes sobrecarga física e psíquica, levando ao surgimento de emoções negativas, como medo, angústia, ansiedade, depressão, indignação, frustração por não conseguir salvar vidas apesar dos esforços. Outro aspecto importante que tem sido notado são as avaliações cognitivas negativas, onde os profissionais têm se mostrado mais sensíveis aos riscos sociais, apresentado diminuição da felicidade e da satisfação com a vida, podendo chegar a extremos como o delírio, psicose e suicídio ${ }^{(7,8,20)}$.

Também deve ser observado que as equipes da linha de frente foram sobrecarregadas pela necessidade de interfacear as demandas emocionais de familiares e acompanhantes, pois as rigorosas medidas para contenção da infecção faz com que o contato direto entre o psicólogo e as pessoas que têm COVID-19 seja raro nos locais com maiores índices de contaminação ${ }^{(21)}$.

Com essas mudanças de saúde e adoecimento, um número maior de problemas e demandas do trato psicológico e emocional aconteceu, fazendo-se necessário lidar com questões no processo de morte e morrer, sendo que, os profissionais de
Também deve ser observado que as equipes da linha de frente foram

sobrecarregadas

pela necessidade

de interfacear

as demandas

emocionais de

familiares e

acompanhantes, pois

as rigorosas medidas

para contenção da

infecção faz com

que o contato direto

entre o psicólogo e

as pessoas que têm

COVID-19 seja

raro nos locais com

maiores índices de

contaminação. saúde precisam cuidar dos sintomas estressores diante dessa realidade, para evitar o adoecimento psíquico ${ }^{(8)}$.

No momento mais intenso da Pandemia no Brasil foi noticiadas dificuldades na aquisição de insumos e equipamentos de proteção individual (EPI), assim como também foi registrado o maior índice de licenças médicas a profissionais da saúde, na comparação entre a primeira e a segunda quinzena de março de $2020^{(7)}$. Esse fato também pode ser observado na instituição em questão, onde se teve um aumento do número de atestados em relação aos sintomas gripais, mas também teve um aumento dos atestados por causas relacionadas a sintomas e sinais relativos ao estado emocional, o que chamou a atenção e levou à instituição a necessidade de pensar em como trabalhar suas equipes nesse momento.

A Portaria $n^{\circ} 639$, de 31 de março de 2020, dispõe sobre a Ação Estratégica "O Brasil Conta Comigo - Profissionais da Saúde", voltada à capacitação e ao cadastramento de profissionais da área de saúde, para o enfrentamento à pandemia do coronavírus (COVID-19)"(22). Essa foi uma estratégia do Ministério da Saúde, porém não tinha enfoque na parte emocional das equipes de trabalho, mesmo assim a instituição encorajou a suas equipes a participarem desse momento, pois nessa formação se trabalhava os protocolos de biossegurança e cuidados na assistência ao paciente COVID-19, o que era uma ação de promoção da saúde importante para evitar a contaminação das equipes.

O trabalho do psicólogo junto às equipes da saúde pode colaborar na promoção da saúde mental e prevenção de implicações psicológicas negativas a esses profissionais, ao oferecer o suporte e orientação sobre como lidar com os casos de pessoas que não aceitam seu diagnóstico e logo não aderem às recomendações e tratamento, assim como trabalhar a aceitação do profissional em se deparar com a situação onde não conseguir sempre salvar vidas e o distanciamento da família e amigos ${ }^{(7)}$.

Diante do cenário de pandemia, a instituição identificou, que, a preservação da saúde de seus profissionais - onde se 
mantiveram trabalhando com maior intensidade de atividades, responsabilidades

e exposição diária a situações de estresse - não era apenas de promoção, prevenção

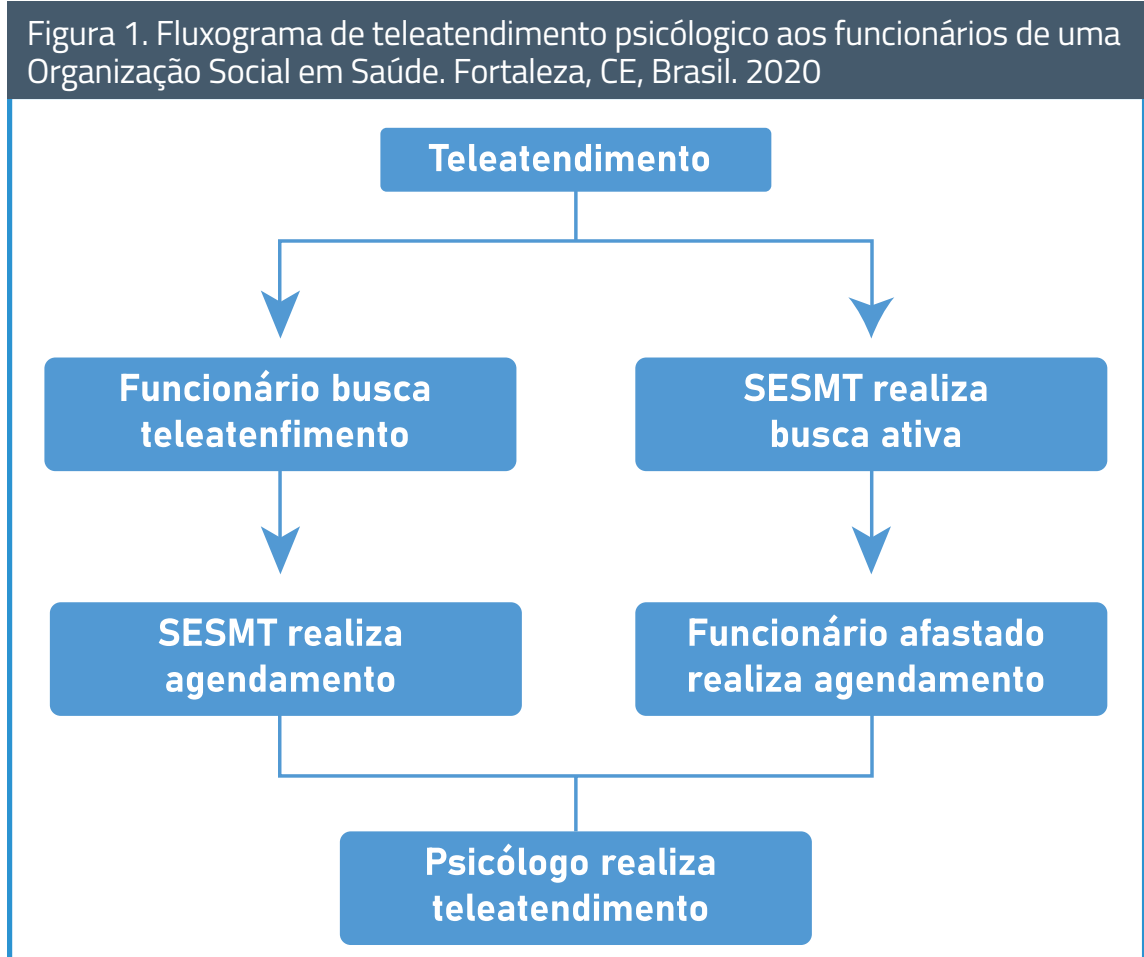

Fonte: Elaborado pelo autor, 2020.

Figura 2. Orientação frente ao teleatendimento psicólogico ao funcionários de uma Organização Social em Saúde. Fortaleza, CE, Brasil. 2020.

1- 0 objetivo do projeto é proporcionar o acolhimento aos profissionais de saúde diante das circunstâncias de trabalho oriundas no enfrentamento ao COVID-19, portanto, não tratando-se de Psicoterapia.

2- 0 projeto é destinado aos profissionais da OSS e das unidades geridas: UPA, APS e Sede;

3- 0 psicõlogo voluntário realizarã o contao via WhatsApp chamada de vídeo;

4- Todos os agendamentos com os Psicólogos voluntários só serão realizados via SESMT da OSS;

5- 0 profissional da OSS poderá ter 01 atendimento por semana, caso o mesmo necessite de novo atendimento, respeitado o periodo semanal, deverá entrar em contato com o SESMT da OSS;

6- Dia e horário da sessão dever ser estritamente respeitados pelo funcionários da OSS;

7- A sessão tem duração de $\mathbf{5 0}$ minutos, e no dia e horário deverá aguardar o contato do Psicólogo voluntário, devendo está em local reservado para proteção e confidencialidade das informações;

8- Todos os atrados ocorridos para início do atendimento, por indisponiflidade do colaborador, o atendimento seguirá até o horário final da sessão. Recomendar ao colaborador a pontualidade na utilização de seu afendamento;

9- 0 aconselhamento com o Psicólogo não gera nenhum tipo de atesto médico;

10- Após a realização da sessão, a OSS orienta que o telefone do Psicólogo não seja divulgado nem disponibilizado, reforçado que todos os agendamentos são realizados apenas via SESMT da OSS.

Fonte: Elaborado pelo autor, 2020. e tratamento no âmbito físico, mas, também, no trato psicológico e emocional. Tornou-se tão quanto fundamental controlar a disseminação da doença no efetivo profissional, como também, proporcionar uma escuta terapêutica e psicológica que pudesse aliviar o medo e a angústia, dando espaço e apoio para que os profissionais de saúde pudessem partilhá-los e receber orientação profissional, permitindo assim, a busca de estratégias no enfrentamento as próprias emoções, para que a saúde mental pudesse ser cuidada.

A experiência em questão passou pelos mesmos desafios apontados acima pela literatura, o grupo gestor começou a perceber o aumento dos números de atestados e conflitos nas unidades e nesse momento surgiu à ideia de pensar num modelo de apoio ao funcionário, que não pode ficar em casa em Home Office, se sentindo acolhido, cuidado e protegido pela instituição.

Portanto, foi ofertado aos profissionais assistenciais e administrativos da OSS um serviço de escuta emocional e psicológica por meio de profissionais voluntários da área de psicologia. A participação dos funcionários no atendimento psicológico deu-se por adesão espontânea ou por busca ativa do SESMT junto aos funcionários afastados por suspeita ou confirmação de infecção relacionada à COVID-19, o fluxo fica descrito na Figura 1.

Em ambos os modelos de adesão, passiva ou ativa, a equipe gestora do projeto dispunha de informações que tinham o cunho de obrigatoriedade a serem repassadas ao funcionário demandante de atendimento, buscando assim a organização dos atendimentos, a boa gestão da agenda de horários disponíveis dos profissionais voluntários, o reforço quanto a segurança, confidencialidade e sigilo de todas as informações, preservação dos números de telefone dos profissionais voluntários, fluxo de agendamento, bem como, para acompanhamento e análise das demandas, como descritas na Figura 2.

Alguns desafios foram enfrentados pela OSS durante o projeto, podendo-se destacar: composição do time de psicólogos externos à instituição para 


\section{artigo}

Barbosa, J.R.M.; Alves, J.S.M.; Reis, V.A.S.; Figueiredo, L.M.L.L.; Batista, R.B.; Severino, F.G.;

Teleatendimento como ferramenta de apoio profissional: acolhimento e escuta emocional na pandemia CoVID-19

atendimento voluntário; propagação e disseminação do projeto em meio ao momento caótico de pandemia, tanto pelo excesso de tarefas exigidas e o caráter emergencial do período, quanto pela necessidade urgente de implantação do projeto; adesão dos profissionais ativos e afastados às intervenções propostas; a impossibilidade dos profissionais no cumprimento dos agendamentos para momento de escuta psicológica devido a sobrecarga de trabalho, bem como, o volume de remarcações; e, o próprio modelo de oferta dos atendimentos, via online, que demandou tanto dos profissionais da área de psicologia, quanto dos funcionários da OSS, ajustes ao formato de teleatendimento.

\section{Relevância do teleatendimento no cenário de Pandemia}

A pandemia tem representado um desafio aos sistemas de saúde e a utilização de Tecnologia da Informação e Comunicação (TIC) tem sido manejada nas estratégias do teleatendimento como uma ferramenta para ampliar a prestação de serviços as pessoas no atendimento psicológico remoto como mecanismo para o acolhimento as queixas relacionadas à saúde mental. Dadas as rigorosas recomendações, o teleatendimento auxilia na promoção da saúde psicológica das pessoas em um momento de urgência e calamidade pública, promo- vendo a aproximação com profissionais da área de psicologia, vindo a contribuir para o fortalecimento de uma rede de apoio ${ }^{(10,23)}$.

Tal tecnologia é considerada um recurso fundamental por reduzir o risco de contaminação de pessoas e a propagação da doença, possibilitando o atendimento às pessoas hígidas ou portadoras de doenças e comorbidades preexistentes que, embora não infectados, não poderiam comparecer pessoalmente a um atendimento psicológico ${ }^{(24)}$.

O teleatendimento está sendo uma solução factível para os tempos atuais e a facilidade ocasionada pelo atendimento a distância possibilitou tanto a adesão quanto participação dos psicólogos no voluntariado, possibilitando a participação deles em suas casas; como a participação dos funcionários, que podiam participar de suas casas, também, nos seus momentos de descanso.

Os desafios encontrados pelo projeto durante o teleatendimento foram as questôes relacionadas às oscilações da internet, gerando interrupções do momento, estes, quando aconteciam, eram avaliados pelos psicólogos responsável e tinha a possibilidade de ser remarcado, se o mesmo considerasse que não tinha sido proveitoso o momento. Outro desafio foi a resistência dos participantes ao modo de teleatendimento, que era superado pela conversa junto ao SESMT e o alinhamento entre os psicólogos voluntários, onde foi criado um grupo de WhatsApp onde era um local para tirar dúvidas e trocar experiências que foram surgindo no percurso do projeto, sempre prezando pelo sigilo e anonimato dos atendimentos.

\section{CONCLUSÃO}

$\mathrm{Na}$ experiência vivenciada foi percebido a importância da escuta qualificada por um psicólogo na ajuda aos funcionários nesse momento pandêmico e de intensa atividade. Foi evidenciada pela equipe do projeto uma carência por cuidados voltados ao trato psicológico dos profissionais da área da saúde, principalmente, no contexto de calamidade pública e com intensos fatores estressores.

O uso de Tecnologia de Informação e Comunicação (TIC) teve papel fundamental na aproximação do profissional voluntário de psicologia com o funcionário da OSS, que no contexto se encontrava, em muitos casos, longe de familiares e amigos, apreensivos com a situação de Pandemia e o risco diário de contaminação com o vírus. Através de seu uso, a OSS pode cuidar de seus funcionários de forma urgente, com cautela, cuidado, ética, respeito, buscando sempre proporcionar o melhor acolhimento e escuta emocional, na tentativa de reduzir o excesso de estresse e outros sintomas que geram algum tipo de angústia e aflição. -

\section{REFERÊNCIAS}

1. Werneck GL, Carvalho MS. A pandemia de COVID-19 no Brasil: crônica de uma crise sanitária anunciada. Caderno Saúde Pública [Internet]. 2020 [citado em 27 de novembro de 2020]; 36 (5): e00068820. Disponivel em: http://www.scielo.br/scielo. php?script=sci_arttext\&pid=S0102-311X2020000500101\&lng=en. Epub em 08 de maio de 2020 . https://doi. org/10.1590/0102-311x00068820.

2. Souza DO. A pandemia de COVID-19 para além das Ciências da Saúde: reflexões sobre sua determinação social. Ciênc. saúde coletiva [Internet]. 2020 June [cited 2020Nov 27] ; 25 (Suppl 1): 2469-2477. Availablefrom: http://www.scielo.br/scielo. php?script=sci_arttext\&pid=S1413-81232020006702469\&Ing=en. EpubJune 05, 2020. https://doi.org/10.1590/141381232020256.1.11532020.
3. Brasil. Ministério da Saúde. Boletim Epidemiológico. Coronavírus Brasil. Painel de casos de doença pelo coronavírus 2019 (COVID-19) no Brasil pelo Ministério da Saúde [Internet]. Brasília; 2020 [citado em 12 agosto 2020].

4.FaroA,BahianoMA, NakanoTC, ReisC, SilvaBFP, VittiLS.COVID-19 e saúde mental: a emergência do cuidado. Estudos de Psicologia (Campinas) [Internet]. 2020 [citado em 27 de novembro de 2020]; 37, e200074. Disponivel em: http://www.scielo.br/scielo. php?script=sci_arttext\&pid=S0103-166X2020000100507\&Ing=en\&nrm=iso.EpubJune $\quad 01, \quad 2020 . h t t p s: / / d x . d o i$. org/10.1590/1982-0275202037e200074.

5. Ceará. Secretaria de Saúde do Estado do Ceará. Profissionais de saúde adaptam rotina em meio à pandemia [Internet]. Fortaleza; 2020 [citado em 13 agosto 2020]. Disponivel em: https:// 


\section{REFERÊNCIAS}

www.saude.ce.gov.br/2020/04/21/profissionais-de-saudeadaptam-rotina-em-meio-a-pandemia/.

6. Almeida IM. Proteção da saúde dos trabalhadores da saúde em tempos de COVID-19 e respostas à pandemia. Rev. bras. saúde ocup. [Internet]. 2020 [cited 2020 Nov 27] ; 45: e17. Availablefrom: http://www.scielo.br/scielo.php?script=sci_arttext\&pid=S0303-76572020000101500\&lng=en. EpubJune 10, 2020. https://doi.org/10.1590/scielopreprints.140.

7. Schmidt B, Crepaldi MA, Bolze SDA, SILVA LN, Demenech LM. Saúde mental e intervenções psicológicas diante da pandemia do novo coronavírus (COVID-19). Estudos de Psicologia (Campinas) [Internet]. 2020 [citado em 27 de novembro de 2020]; 37, e200063. Disponivel em: <http://www.scielo.br/scielo. php?script=sci_arttext\&pid=S0103-166X2020000100501\&l ng=en\&nrm=iso>. Epub May 18, 2020.https://doi. org/10.1590/1982-0275202037e200063.

8. Lima AM, Carvalho CMSM, Angelo LM, Oliveira MA, Silva PCPO, Santos RGS, Silva ROC. Relações entre a pandemia de COVID-19 e a saúde mental dos profissionais de enfermagem. Saúde Coletiva (Barueri). 2020; 10(54): 2699-2706.

9. Brasil. Presidência da República. Lei n 9.608, de 18 de fevereiro de 1998. Brasilia; 1998. Disponivel em:http://www.planalto.gov.br/ccivil_03/leis/l9608.htm.

10. Escola de Saúde Pública do Ceará. Atendimento psicológico online no contexto da Pandemia de COVID-19. Disponível em:https://cadernos.esp.ce.gov.br/index.php/cadernos/article/ view/399/215

11. Conselho Federal de Psicologia. Nova Resolução do CFP orienta categoria sobre atendimento on-line durante pandemia da Covid-19[Internet]. Brasília, DF; 2020. Disponivel em: https:// site.cfp.org.br/nova-resolucao-do-cfp-orienta-categoria-sobre-atendimento-on-line-durante-pandemia-da-covid-19/.

12. Conselho Federal de Psicologia. Instrução Normativa $n^{\circ} 1$, de 17 de março de 2020. [Internet]. Brasília, DF 2020. Disponivel em:https://atosoficiais.com.br/cfp/instrucao-normativa-n-1-2020-dispoe-sobre-a-suspensao-dos-prazos-processuais-e-prescricionais-no-ambito-do-conselho-federal-de-psicologia-e-dos-conselhos-regionais-de-psicologia?origin=instituicao.

13. Conselho Federal de Psicologia. Institui a regulamentação da Escuta Psicológica de Crianças e Adolescentes envolvidos em situação de violência, na Rede de Proteção. [Internet]. Brasilia, DF;2010. Disponivel em: http://site.cfp.org.br/wp-content/uploads/2010/07/resolucao2010_010.pdf.

14. Conselho Regional de Psicologia do Paraná. Nota técnica 003-2018. Orienta os profissionais psicólogos sobre a atuação profissional em atendimento à lei $n^{\circ} 13.431 / 2017$. [Internet]. Curitiba, PR;2018.

15. Conselho Federal de Psicologia. Resolução $n^{\circ}$ 10, de 20 de dezembro de 2000 [Internet]. Brasília, DF; 2000. Disponível em: https://site.cfp.org.br/wp-content/uploads/2000/12/resolucao2000_10.pdf.
16. Morais $A D$, Lima ACS, Gomes IF, Franca JM, Oliveira MN. Serviço de escuta psicológica: Uma escuta profunda de caráter emergencial. Encontro de Extensão da Universidade Federal da Paraíba. João Pessoa, PB. Disponível em: http://www.prac.ufpb. br/enex/trabalhos/6CCHLADPFLUEX2013820.pdf.

17. Mesquita AC, Carvalho EC de. A Escuta Terapêutica como estratégia de intervenção em saúde: uma revisão integrativa. Rev. esc.enferm. USP [Internet]. 2014 Dec [cited 2020 Nov29]; 48(6): 1127-1136. Availablefrom: http://www.scielo.br/scielo. php?script=sci_arttext\&pid=S0080-62342014000601127\&Ing=en. https://doi.org/10.1590/S0080-623420140000700022.

18. Conselho Federal de Psicologia. Código de Ética da Psicologia. [Internet]. Brasília, DF;2005. Disponível em: https://site.cfp. org.br/legislacao/codigo-de-etica/.

19. Fiho José Marçal Jackson, Assunção Ada Ávila, Algranti Eduardo, Garcia Eduardo Garcia, Saito Cézar Akiyoshi, Maeno Maria. A saúde do trabalhador e o enfrentamento da COVID-19. Rev. bras. saúde ocup. [Internet]. 2020 [cited 2020 Nov 29]; 45: e14. Availablefrom: http://www.scielo.br/scielo.php?script=sci_arttext\&pid=S0303-76572020000100100\&Ing=en. Epub Apr 17, 2020. https://doi.org/10.1590/2317-6369ed0000120.

20. Baron MV, PalagiVigano AJ, Di Lorenzo Garcia Scherer G, Knorr Velho I, Martins Dantas Santos M, Braga da Silveira J, Pinheiro da Costa BE. Impactos da COVID-19 na saúde mental da população chinesa no início da epidemia: Revisão Integrativa. SaudColetiv (Barueri) [Internet]. $6^{\circ}$ de agosto de 2020 [citado $29^{\circ}$ de novembro de 2020];10(54):2661-78. Disponivel em: http://www.revistas.mpmcomunicacao.com.br/index.php/saudecoletiva/article/view/736.

21. Jiang $X$, Deng $L$, Zhu $Y$, Ji $H$, Tao $L$, Liu $L$ et al. (2020). Psychologicalcrisisinterventionduringtheoutbreakperiodof new coronavirus pneumonia fromexperience in Shanghai. PsychiatryResearch, 286, 112903. http://dx.doi. org/10.1016/j.psychres.2020.112903.

22. Ministério da Saúde. (2020b). Portaria n 639, de 31 de março de 2020. Dispõe sobre a Ação Estratégica "O Brasil Conta Comigo - Profissionais da Saúde", voltada à capacitação e ao cadastramento de profissionais da área de saúde, para o enfrentamento à pandemia do coronavírus (COVID-19). Diário Oficial da União. Brasília: Autor. Disponivel em: http://www.in.gov.br/en/web/ dou/-/portaria-n-639-de-31-de-marco-de-2020-250847738.

23. Schmidt B et al. Saúde mental e intervenções psicológicas diante da pandemia do novo coronavírus (COVID-19). Estud. psicol. (Campinas) [online]. 2020, vol.37, e200063. Epub May 18, 2020. ISSN 1982-0275. https://doi.org/10.1590/19820275202037 e200063.

24. Caetano R, Silva AB, Guedes ACCM, Paiva CCN de, Ribeiro GR, Santos DL et al. Desafios e oportunidades para telessaúde em tempos da pandemia pela COVID-19: uma reflexão sobre os espaços e iniciativas no contexto brasileiro. Cad. Saúde Pública [Internet]. 2020 [cited 2020Nov 29] ; 36( 5 ): e00088920. Availablefrom: http://www.scielo.br/scielo.php?script=sci_arttext\&pid=S0102-311X2020000503001\&lng=en. EpubJune 01, 2020. https://doi.org/10.1590/0102-311x00088920. 